\title{
Article \\ Nafion and Multiwall Carbon Nanotube Modified Ultrananocrystalline Diamond Microelectrodes for Detection of Dopamine and Serotonin
}

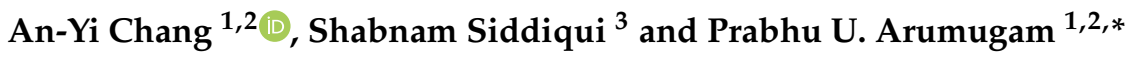 \\ 1 Institute for Micromanufacturing (IfM), Louisiana Tech University, Ruston, LA 71272, USA; \\ aychang73@gmail.com \\ 2 Center for Biomedical Engineering and Rehabilitation Science (CBERS), Louisiana Tech University, \\ Ruston, LA 71272, USA \\ 3 Department of Chemistry and Physics, Louisiana State University Shreveport, Shreveport, LA 71115, USA; \\ Shabnam.Siddiqui@lsus.edu \\ * Correspondence: parumug@latech.edu
}

Citation: Chang, A.-Y.; Siddiqui, S.; Arumugam, P.U. Nafion and Multiwall Carbon Nanotube Modified Ultrananocrystalline Diamond Microelectrodes for Detection of Dopamine and Serotonin. Micromachines 2021, 12, 523. https://doi.org/10.3390/mi12050523

Academic Editor: Seong-O Choi

Received: 27 March 2021

Accepted: 3 May 2021

Published: 6 May 2021

Publisher's Note: MDPI stays neutral with regard to jurisdictional claims in published maps and institutional affiliations.

Copyright: (c) 2021 by the authors. Licensee MDPI, Basel, Switzerland. This article is an open access article distributed under the terms and conditions of the Creative Commons Attribution (CC BY) license (https:// creativecommons.org/licenses/by/ $4.0 /)$.

\begin{abstract}
Neurochemicals play a critical role in the function of the human brain in healthy and diseased states. Here, we have investigated three types of microelectrodes, namely boron-doped ultrananocrystalline diamond (BDUNCD), nafion-modified BDUNCD, and nafion-multi-walled carbon nanotube (MWCNT)-modified BDUNCD microelectrodes for long-term neurochemical detection. A $\sim 50$ nm-thick nafion-200-nm-thick MWCNT-modified BDUNCD microelectrode provided an excellent combination of sensitivity and selectivity for the detection of dopamine (DA; $6.75 \mu \mathrm{A} \mu \mathrm{M}^{-1} \mathrm{~cm}^{-2}$ ) and serotonin (5-HT; $4.55 \mu \mathrm{A} \mathrm{\mu M}^{-1} \mathrm{~cm}^{-2}$ ) in the presence of excess amounts of ascorbic acid (AA), the most common interferent. Surface stability studies employing droplet-based microfluidics demonstrate rapid response time $(<2 \mathrm{~s})$ and low limits of detection $(5.4 \pm 0.40 \mathrm{nM})$. Furthermore, we observed distinguishable DA and 5-HT current peaks in a ternary mixture during long-term stability studies (up to $9 \mathrm{~h}$ ) with nafion-MWCNT-modified BDUNCD microelectrodes. Reduced fouling on the modified BDUNCD microelectrode surface offers significant advantages for their use in long-term neurochemical detection as compared to those of prior-art microelectrodes.
\end{abstract}

Keywords: neurochemical; electrochemistry; microfluidic; carbon nanotube; diamond; microsensors; nafion

\section{Introduction}

Understanding the role of neurochemicals in the functioning of the human brain in both healthy and diseased states is critical to the development of new and effective therapies for numerous neurodegenerative diseases [1]. Abnormal levels of neurochemicals such as dopamine (DA), serotonin (5-HT), glutamate, and GABA are the primary cause of epilepsy, Parkinson's disease, traumatic brain injury, drug addiction, and many others [2-4]. DA is an important catecholamine in the mammalian central nervous system [3], because it is a central player in the brain "reward" system and plays a critical role in various bodily functions, i.e., motor control, motivation, and cognition, and in several debilitating neuropathologies [1,4]. Levels of 5-HT are linked to depression, addiction, and other functions ranging from appetite to sleep [5]. Electrochemical microsensors have been successfully employed to investigate the role of neurochemicals in real time [6]. Since DA and 5-HT are electrochemically active, they are readily and directly measured at physiologically relevant concentrations using electrochemical techniques such as cyclic voltammetry (CV), amperometry, differential pulse voltammetry (DPV), and fast-scan cyclic voltammetry with excellent spatial (micron range) and temporal (sub-second range) resolution in vitro and in vivo [7]. These methods routinely use carbon-fiber microelectrodes and glassy carbon electrodes with sub-micromolar sensitivity [8,9]. Among the emerging electrode materials 
for electrochemical microsensors, carbon nanomaterials such as carbon nanotubes [10-13], carbon nanofibers [14-16], micro- and nanocrystalline diamond [17-19] are frequently used to detect neurochemicals with either high sensitivity and/or high selectivity. Single-wall and multi-wall carbon nanotubes (SWCNTs and MWCNTs, respectively) have been widely used to detect neurochemicals by significantly increasing electroactive/adsorption sites for higher sensitivity and electrocatalytic/defect-rich sites for higher selectivity detection. In most cases, nanotubes have been used to modify existing electrodes such as carbon-fiber microelectrodes, graphite, glassy carbon electrode, carbon paste, and diamond-like carbon to increase adsorption sites, decrease oxidation overpotentials and improve sensitivity [4,9-12].

One of the grand challenges for the chemical neuroscience field is to develop a neurochemical microsensor that has a useful lifetime in the order of several hours or days, so that a more meaningful understanding of brain disorder mechanisms can be gained [20]. The useful lifetime of carbon-nanomaterial-enabled microsensors is generally extended due to their high resistance from chemical etching and little surface fouling due to by-products such as melanin and dimers generated from neurochemical oxidation [21,22]. The carbonfiber microelectrode, which is the current gold-standard electrode material, is not suitable for chronic neurochemical recording due to their susceptibility towards surface fouling and degradation $[22,23]$. On the contrary, previous studies have shown that conductive boron-doped polycrystalline diamond has excellent electrochemical properties-superior chemical inertness and dimensional stability, a wide electrochemical potential window, extremely low background currents, exceptional biocompatibility for brain chemical sensing $[1,13,14]$, and most importantly, greater surface fouling resistance than other forms of nanocarbon electrode materials [24].

In this study, we have microfabricated and fully characterized a nafion-coated hybrid MWCNT film-modified boron-doped ultrananocrystalline diamond (BDUNCD) microelectrode for long-term DA and 5-HT detection in the presence of ascorbic acid (AA). Nafion was chosen to block anionic molecules such as AA, although with an increase in the response time of analyte measurements [25]. A 2- $\mu$ m-thick BDUNCD thin film was chosen as the bare microelectrode material because of its unique nanoscaled structure-ultra-small equiaxed grains (2-5 nm in diameter) and inherently ultra-smooth surface $\left(\mathrm{R}_{\mathrm{a}}: \sim 5-8 \mathrm{~nm}\right.$ root mean square (rms)) [12]. Several groups including ours have used microlithographic techniques to produce well-defined, reproducible microelectrode geometries on BDUNCD films and wires for in vitro and in vivo neurochemical measurements [15-19,26]. MWCNTs were chosen as a modifying layer for the BDUNCD electrode surface because of its ballistic electronic properties, high surface area, excellent interfacial adsorption properties, and enhanced electrocatalytic activity. Several techniques have been employed previously to modify surfaces with carbon nanotubes, namely, chemical vapor deposition, drop casting, and electrophoretic deposition (EPD) [21,22]. Chemical vapor deposition processes are quite expensive, involving cumbersome microfabrication processes, costly cleanroom equipment, and high temperature growth processes that severely limit electrode and electrode substrate material choices [22-27]. Drop casting neither controls the thickness nor achieves a highly selective, uniform coating thickness on microelectrode surfaces [22]. However, EPD is well suited to deposit charged particles such as nanotubes with highly controllable coating thicknesses and the precise integration of the coating onto the microelectrode surface [24]. In this work, MWCNT films were selectively coated on 250- $\mu$ m-diameter BDUNCD microelectrodes using EPD.

Furthermore, we have integrated a microfluidic platform to study the surface modified BDUNCD microelectrodes and changes in their sensor performance metrics for up to $9 \mathrm{~h}$. Previous studies have integrated microfluidics with chemical and biological sensors because of their ability to perform multiplexed real-time measurements rapidly with reduced sample volumes, enhanced analyte transport, increased analyte sensitivity, automation, and lower costs [28-31]. Specifically, it provides the capability to inject controllable amounts of different neurochemicals onto the microsensor surface to evaluate its performance more accurately. In this work, we have employed a droplet-based microfluidics platform to 
evaluate the sensor metrics (sensitivity, response time, clearance rate, selectivity, and limit of detection (LOD)) in detail with controllable neurochemical flow rates and volumes and sub-second-to-second changes in the levels of the neurochemicals at the electrode surface that is expected in the brain [32].

\section{Materials and Methods}

\subsection{Microfabrication of the BDUNCD Microelectrode Array}

The substrates employed for these microelectrodes were four-inch silicon wafers with a 1- $\mu$ m-thick thermal silicon dioxide (Wafer World Inc., Palm Beach, FL, USA) surface coating. A 2- $\mu$ m-thick BDUNCD film was then deposited with a hot filament chemical vapor deposition process from Advanced Diamond Technologies, Inc. (Romeoville, IL, USA). The BDUNCD film resistivity was $\sim 0.08 \Omega \cdot \mathrm{cm}$ as measured by a 4 -point probe from a witness wafer (Pro4, Lucas Labs, Gilroy, CA, USA). The average roughness of the BDUNCD film was $<10 \mathrm{~nm}$ rms based on AFM measurements (Digital Instruments, Santa Barbara, CA, USA). Optical microlithography was used to pattern 21 chips per wafer. Each chip was micro-patterned into nine individually electrically addressable 250 - $\mu \mathrm{m}$-diameter disk microelectrodes (geometrical area: $\sim 0.05 \mathrm{~mm}^{2}$ ) in a $3 \times 3$ microelectrode array format, shown in Figure 1a,d (details described elsewhere) [12,33].
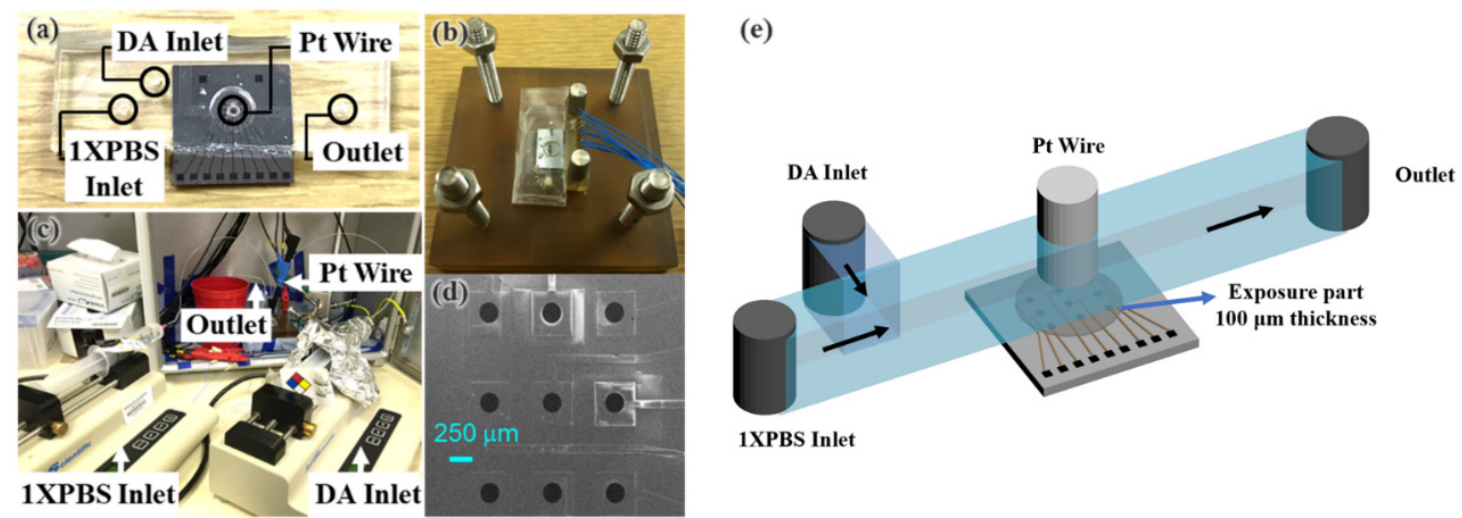

Figure 1. (a) Optical picture of an integrated boron-doped ultrananocrystalline diamond (BDUNCD) chip-microfluidic platform. (b) Optical picture of an assembled system with electrical connections. (c) Experimental setup showing connections to the micro syringe pumps and the potentiostat. (d) SEM image of a $3 \times 3$ BDUNCD microarray chip. (e) Schematic showing the integration of microfluidics with the BDUNCD chip.

\subsection{Preparation of Nafion and MWCNT Coatings Using EPD}

Both MWCNT and nafion coatings (layers) were deposited by a two-electrode method. BDUNCD was the working electrode, and a platinum microwire (for MWCNT) and an $\mathrm{Ag} / \mathrm{AgCl}$ electrode (for nafion) were the counter and the reference electrode, respectively. A $1 \mathrm{mg} / \mathrm{mL}$ MWCNT suspension in deionized (DI) water (PD15L-5-20, outside diameter (OD): $15 \pm 5 \mathrm{~nm}$, length: $1-5 \mu \mathrm{m}, 5 \%-\mathrm{COOH}$ functionalized; Nanolab, Inc., Waltham, MA, USA) was used for the coating. Before EPD, a $5 \mu \mathrm{M} \mathrm{MgCl}_{2} \cdot 6 \mathrm{H}_{2} \mathrm{O}$ salt solution was added to the MWCNT suspension and sonicated for $30 \mathrm{~min}$. This imparted a positive charge to the MWCNTs [34,35]. A 30 $\mu$ L MWCNT suspension was placed between the BDUNCD chip and the Pt counter electrode. A stepwise voltage scan $(-6 \mathrm{~V})$ was applied using a Gamry reference 600 Potentiostat (Gamry Instruments, Warminster, PA, USA) to the BDUNCD microelectrode for $10 \mathrm{~min}$, and it was then cured at $70{ }^{\circ} \mathrm{C}$ for $10 \mathrm{~min}$ (details described elsewhere) [36]. A 200-nm-thick MWCNT coating (via SEM imaging) was thereby achieved. For nafion coating, a $5 \mathrm{wt} \%$ solution (Sigma Aldrich, St. Louis, MO, USA) was used. A $\sim 20 \mu \mathrm{L}$ nafion solution was placed between the chip and the $\mathrm{Ag} / \mathrm{AgCl}$ counter/reference. A stepwise voltage scan $(+0.5 \mathrm{~V})$ was applied to the microelectrode for 2 min followed by a rinse in deionized water and curing at $70{ }^{\circ} \mathrm{C}$ for $10 \mathrm{~min}$. A $\sim 50$-nm-thick nafion coating (via SEM imaging) was thereby achieved. 


\subsection{Microfabrication of Microfluidic Devices}

A two-layer polydimethylsiloxane (PDMS; Sylgard 184 with a precursor to curing agent weight ratio of 10:1 was purchased from Dow Corning, Inc., Midland, MI, USA) microfluidic chip was constructed and integrated into the BDUNCD chip (Figure 1) with excellent sealing and no fluid leakage. Firstly, the BDUNCD chip was cleaned by acetone, isopropyl alcohol, and deionized water and dried in an oven at $50{ }^{\circ} \mathrm{C}$. Secondly, a $100-\mu \mathrm{m}-$ thick PDMS (1st layer) was formed by mixing PDMS and the curing agent (at a 10:1 volume ratio) and allowing it to cure at $60^{\circ} \mathrm{C}$ for $2 \mathrm{~h}$. The PDMS on top of the microelectrode area and the areas where the fluidic parts were connected were removed using a punch blade (Figure 1a). Another PDMS layer (2nd layer) with a 65- $\mu \mathrm{m}$ thickness was formed on a SU8-2025 epoxy-based photoresist mold that defined the microchannel. This layer was microfabricated by mixing the PDMS and the curing agent (at a 10:1 volume ratio) and allowing it to cure at $60^{\circ} \mathrm{C}$ for $4 \mathrm{~h}$. Then, the PDMS layer with the patterned microchannel was peeled from the SU8 mold, and the inlet, outlet, and counter/reference access holes were fabricated with a punch blade. Finally, the 2nd PDMS layer was bonded to the 1st PDMS layer-BDUNCD chip assembly by applying an oxygen plasma treatment at $40 \mathrm{~W}$ for $20 \mathrm{~s}$ (UVP Blak-Ray $\left.{ }^{\mathrm{TM}} \mathrm{B}-100 \mathrm{AP}\right)$ [37]. The complete integration of microfluidics to the BDUNCD microarray chip is shown in Figure 1e.

\subsection{Electrochemical Measurements}

All electrochemical experiments were carried out with an Autolab potentiostat (PGSTAT 302N, Metrohm USA, Riverview, FL, USA) configured in a two-electrode setup with a Pt microwire coil (Alfa Aesar, Haverhill, MA, USA) counter/reference electrode. The BDUNCD, nafion-BDUNCD, or nafion-MWCNT-BDUNCD microelectrode was configured as the working electrode. The microelectrode surfaces were exposed to the analyte (single component or ternary mixtures) or 1X PBS electrolyte solutions that were pumped into the microfluidic channel using two micro-syringes pumps (KDS100 Infusion Pump-780100, Kats Scientific, Denton, TX, USA) (Figure $1 \mathrm{~b}, \mathrm{c})$. At any given time during an experiment, we applied only one type of sample solution (e.g., 1X PBS, 1X PBS with DA, 1X PBS with 5-HT, or 1X PBS with a mixture of DA and 5-HT solutions) across all the 9 microelectrodes in the array as a continuous flow using one of the two inlets. The microelectrodes were fashioned in a $3 \times 3$ array format with a diameter of $250 \mu \mathrm{m}$ (Figure 1d). For each microarray chip, the electrical isolation of the pads was measured using a two-point probe multimeter. This ensured the integrity of the silicon dioxide passivation, which was essential for stable electrochemical performance. Prior to characterization, the BDUNCD microelectrode array was briefly sonicated in ethanol for $30 \mathrm{~s}$ and dried in nitrogen. Differential pulse voltammograms were recorded with a 20-mV modulation amplitude and 5-mV step potential [38] for selectivity measurements. All experiments were repeated at least 3 times with three different microelectrodes $(n=3)$ for more than one chip. The DPV voltammograms shown below are representative of the data. All solutions were freshly prepared on the same day when the experiments were conducted and purged with nitrogen gas for $5 \mathrm{~min}$ before use.

\section{Results and Discussion}

\subsection{Characterization of Unmodified and Nafion-, and Nafion-MWCNT-Modified BDUNCD Microelectrodes}

Figure 2a,b displays the SEM images of an unmodified and MWCNT-modified BDUNCD microelectrode surfaces with MWCNTs covering almost the entire surface of the microelectrode. After nafion coating (Figure 2c), a heterogenous surface was observed as expected. During the nafion coating process, we observed a $~ 10 \%$ loss of non-specifically attached MWCNTs due to the application of a positive potential towards the BDUNCD working microelectrode. Nevertheless, a careful investigation of the nafion-MWCNT-BDUNCD surface at higher magnifications (Figure $2 \mathrm{~d}-\mathrm{f}$ ) revealed a sufficient, uniform coverage of the two coatings, which is an important criterion for its application in long-term reliable neurochemical monitoring. The fast-scan cyclic voltammetry (FSCV) voltammograms are displayed in 
Figure 3 for the three types of BDUNCD microelectrodes in a $100 \mu \mathrm{M}$ DA solution at a flow rate of $0.2 \mathrm{~mL} / \mathrm{min}$. Table 1 summarizes the important measured FSCV parameters of the microelectrodes. The peak oxidation current $\left(\mathrm{I}_{\mathrm{pa}}\right)$ that is commonly used as the detection signal was $~ 10$-fold higher for the nafion-MWCNT-modified BDUNCD microelectrode than that of the unmodified BDUNCD microelectrode. The nafion coating on the unmodified BDUNCD surface demonstrated a $\sim 4$-fold higher current than that of the unmodified microelectrode. The oxidation peak potential $\left(\mathrm{E}_{\mathrm{pa}}\right)$ marginally increased from $0.78 \pm 0.01 \mathrm{~V}$ for unmodified BDUNCD surfaces up to $0.94 \pm 0.01 \mathrm{~V}$ for nafion-MCNCT-modified BDUNCD surfaces. The large increase in the current signals (and a higher sensitivity) is due to a significant increase in the electroactive area and sites achieved via MWCNT coating $[36,39]$ and the anionic nature of nafion that is expected to adsorb the positively charged DA $[18,40]$. The results suggested the importance of coating both nafion and MWCNT for improving the overall sensitivity of diamond microelectrodes. The next question to investigate is whether the two-coating modification strategy can provide adequate sensitivity and selectivity longterm. For this, we employed a microfluidic setup to thoroughly characterize the three BDUCND microelectrode types using droplet microfluidics that mimics neurochemical discharges in the extracellular space of the brain [41].
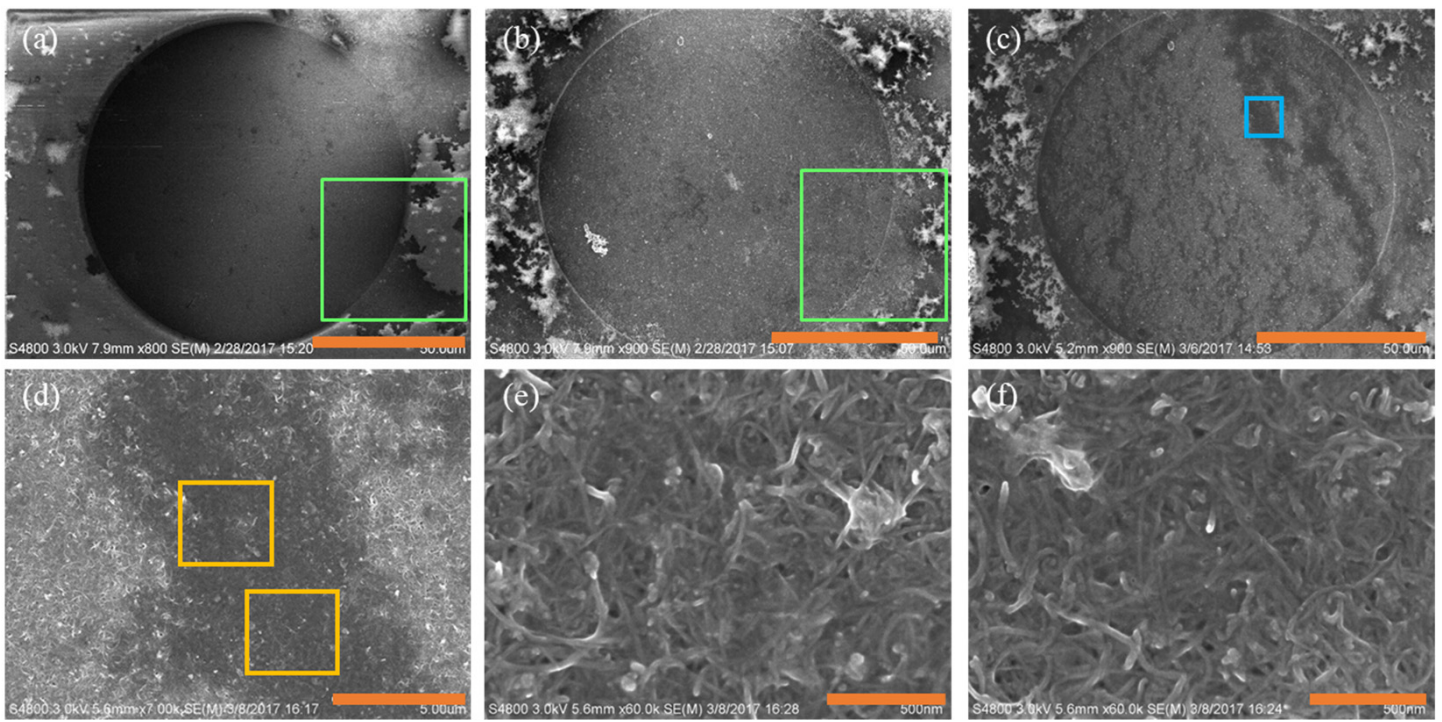

Figure 2. The SEM images of nafion- and nafion-multi-walled carbon nanotube (MWCNT)-coated BDUNCD microelectrodes: (a) unmodified BDUNCD microelectrode; (b) MWCNT-modified BDUNCD deposition at $-6 \mathrm{~V}$ for $10 \mathrm{~min}$; (c) nafion-MWCNT-modified BDUNCD microelectrode at $+1.5 \mathrm{~V}$ for $2 \mathrm{~min}$; (d) nafion-MWCNT-modified BDUNCD electrode at a high magnification image of the region shown in the blue square in (c); (e,f) the two yellow squares shown in (d). The scale bars for (a-f) are 50, 50, 50, 5, 0.5, and $0.5 \mu \mathrm{m}$, respectively.

Table 1. Comparison of $100 \mu \mathrm{M}$ DA peak oxidation and reduction currents and potentials of the cyclic voltammograms from the three types of BDUCND microelectrodes (unmodified, nafion-modified, and nafion-MWCNT-modified BDUCND) $(n=3)$.

\begin{tabular}{cccc}
\hline CV Parameters & BDUNCD & Nafion-BDUNCD & Nafion-MWCNT-BDUNCD \\
\hline $\mathrm{I}_{\mathrm{pc}}(\mu \mathrm{A})$ & $-0.89 \pm 0.04$ & $-3.15 \pm 0.16$ & $-7.87 \pm 0.47$ \\
$\mathrm{I}_{\mathrm{pa}}(\mu \mathrm{A})$ & $0.92 \pm 0.05$ & $2.37 \pm 0.12$ & $9.79 \pm 0.49$ \\
$\mathrm{I}_{\mathrm{pc}} / \mathrm{I}_{\mathrm{pa}}$ & 0.97 & 1.33 & 0.8 \\
$\mathrm{E}_{\mathrm{pc}}(\mathrm{V})$ & $-0.29 \pm 0.01$ & $-0.35 \pm 0.01$ & $-0.8 \pm 0.01$ \\
$\mathrm{E}_{\mathrm{pa}}(\mathrm{V})$ & $0.78 \pm 0.01$ & $0.82 \pm 0.02$ & $0.94 \pm 0.01$ \\
\hline
\end{tabular}




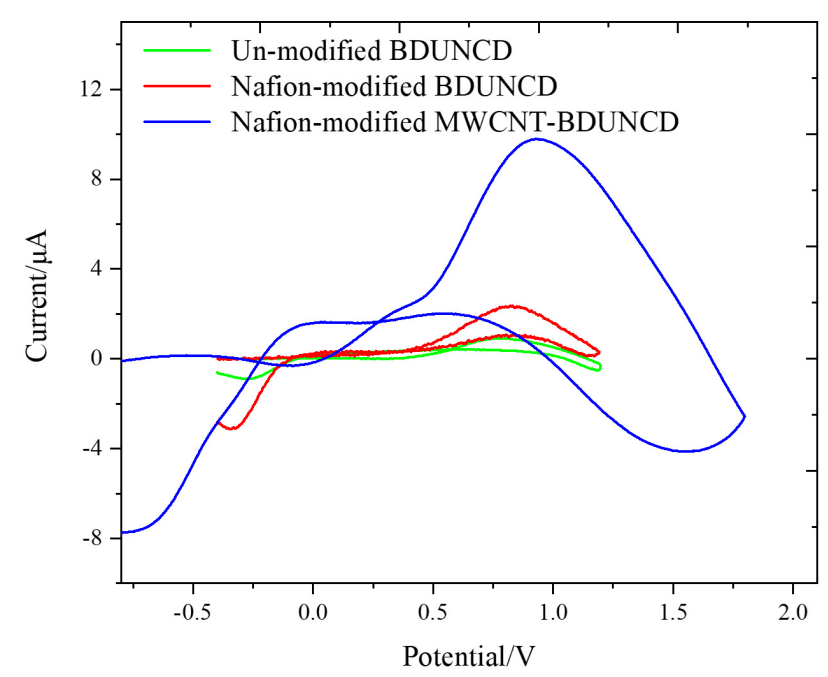

Figure 3. Fast-scan cyclic voltammograms of surface-modified BDUNCD microelectrodes. The green color represents the unmodified BDUNCD microelectrode, the red color represents the nafionmodified BDUNCD microelectrode (red), and the blue color represents the nafion-MWCNT-modified BDUNCD microelectrode. Voltammograms were taken in $100 \mu \mathrm{M}$ dopamine (DA) and 1X PBS buffer at $400 \mathrm{~V} / \mathrm{s}$ and undertook background subtraction. The flow rate was $0.2 \mathrm{~mL} / \mathrm{min}$.

\subsection{Optimization of Droplet Parameters}

We employed microfluidics to pass droplets containing a known analyte concentration over the microelectrode surface using a 1X PBS buffer as the carrying (background) medium. For droplet experiments, we still used only one type of solution but introduced them as droplets using both inlets. In this case, the analyte solution was pumped from one inlet, and the background 1 X PBS was continuously pumped from the other inlet (as shown in Figure 1e). For example, during the 9-h study, we employed 1X PBS for the background continuous fluid flow and introduced the ternary mixture of DA, 5-HT, and AA as droplets at a predetermined frequency (1 droplet per min or 1 droplet every $2 \mathrm{~min}$ ) and with a droplet volume of $0.02 \mathrm{~mL}$. We allowed the droplets to flow over the microarray during the $9 \mathrm{~h}$ experiments. Periodically (every $3 \mathrm{~h}$ ), we stopped the background flow and applied only the analyte solution to flow over the microarray and detected the analytes via DPV. The waiting time between droplets is $2 \mathrm{~min}$, so that the analyte current signal can decrease to background levels. The change in the background currents was monitored for any fouling due to DA by-products such as melanin that was expected to form a thin passivation coating on the electrode surface with time [18]. In addition to the droplet flow rate, its volume is important to optimize and control, as it affects the analyte diffusion within the microchannel and thus, the amplitude and the stability of the current signal. The following optimal conditions that provided a stable signal and flow conditions (details published in 27) were chosen for this work: $0.1 \mathrm{~mL} / \mathrm{min}$ (1X PBS) for the background flow rate, $0.02 \mathrm{~mL}$ for the droplet volume with $100 \mu \mathrm{M} \mathrm{DA}$ concentration, and $+0.35 \mathrm{~V}$ for the applied potential (vs. a Pt microwire).

\subsection{Evaluation of the DA Sensitivity, Response Time, and Clearance Rate Using Droplets}

The long-term changes in the key sensor metrics (peak current, sensitivity, response time, and clearance rate) as defined in Figure 4 is shown in Figure 5 for the three microelectrode types. During the experiments, five measurements were obtained every $30 \mathrm{~min}$ for up to $9 \mathrm{~h}$. The microchannel width was $1800 \mu \mathrm{m}$, and the droplets' volume was $0.02 \mathrm{~mL}$ (100 $\mu \mathrm{M}$ DA) with a background flow rate of $0.1 \mathrm{~mL} / \mathrm{min}$ (1X PBS). Each droplet was introduced every $2 \mathrm{~min}$ into the microchannel and as present over top of the microelectrode for $\sim 5 \mathrm{~s}$. The DA's oxidation peak currents were determined from the second peak, which did not vary by the mass transfer effects within the microchannel [18]. The first peak varied due to the mass transfer effect, which resulted in an unstable peak current signal. Other 
possible causes for the variation in the first peak's oxidation potential variation are the flow conditions and changes in the input solution volume [18]. Therefore, for improved precision in the analysis, we considered only the second peak, which was stable irrespective of the changes in the flow conditions and volume. Sensitivity was defined as the peak current divided by the DA concentration and the electrode area $\left(\mu \mathrm{A} \mu \mathrm{M}^{-1} \mathrm{~cm}^{-2}\right)$. The time delay between the start of the rising peak and the second peak was used to calculate the response time. The time between $20\left(\mathrm{~T}_{20}\right)$ and $60 \%\left(\mathrm{~T}_{60}\right)$ of the falling peak was used to calculate the clearance rate, i.e., the time for the DA signal to decrease to background levels.

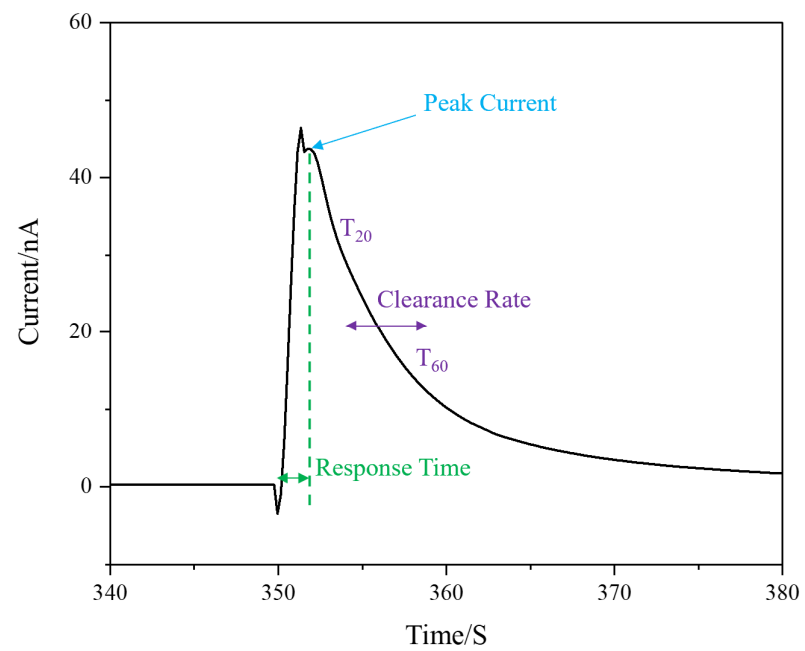

Figure 4. A sample DA signal arising from a single droplet flow across the microelectrode. The method shown was employed for calculating the sensitivity, response time, and clearance rate.
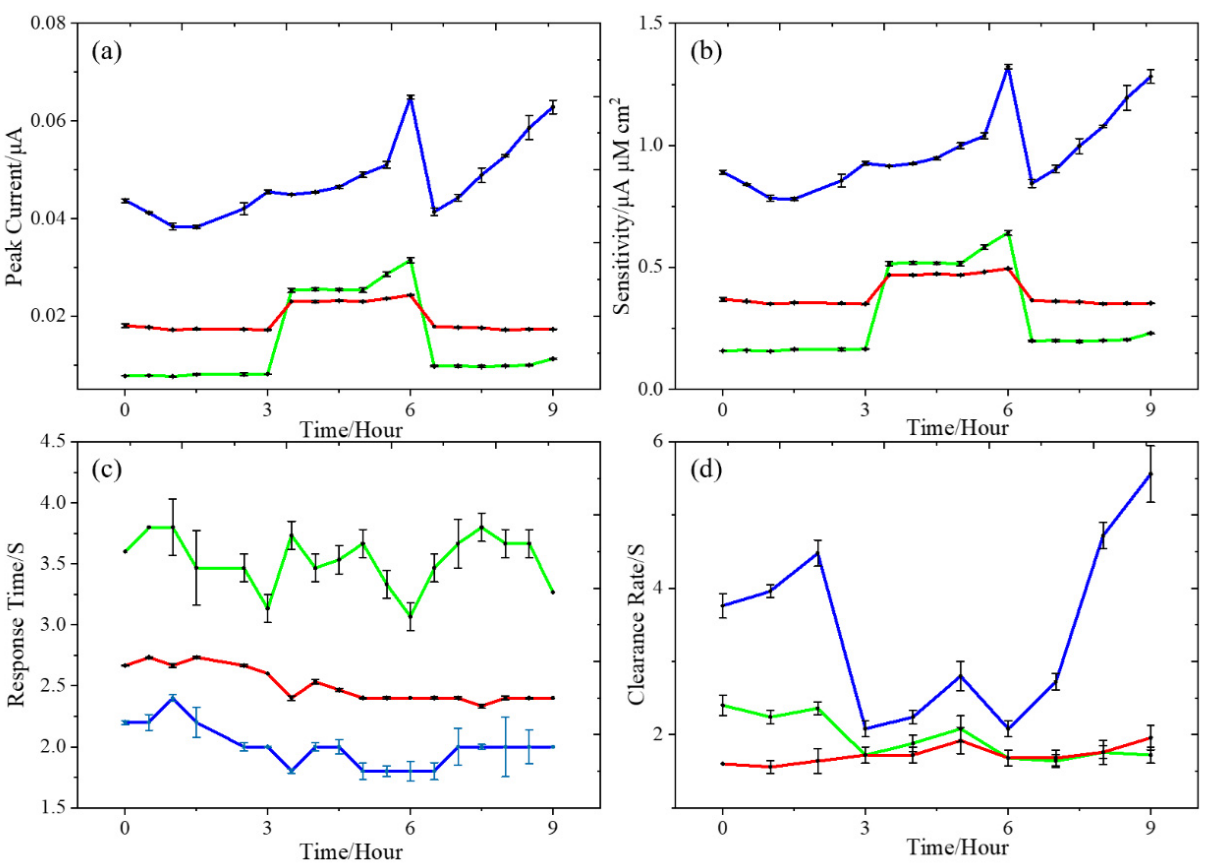

Figure 5. Long-term evaluation of three BDUNCD microelectrode types in terms of (a) peak currents, (b) sensitivity, (c) response time, and (d) clearance rates. Experimental conditions: 1 droplet per min with a background flow rate of $0.1 \mathrm{~mL} / \mathrm{min}$ in $1 \mathrm{X}$ PBS) and $0.02 \mathrm{~mL}(100 \mu \mathrm{M}, \mathrm{DA})$ droplet volume. The applied potential was $+0.35 \mathrm{~V}$ vs. Pt microwire; every $30 \mathrm{~min}$ we took five signals and calculated the error bar in the 9-h experiment. The green color represents the unmodified BDUNCD microelectrode, the red color represents the nafion-modified BDUNCD microelectrode, and the blue color represents nafion-MWCNT-modified BDUNCD microelectrode. 


\subsubsection{Sensitivity}

The DA signal was stable during the first $3 \mathrm{~h}$ of the experiment for the unmodified BDUNCD microelectrode. However, the peak current signal and sensitivity increased

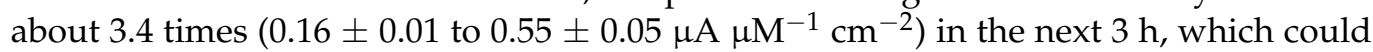
be due to the activation and regeneration of BDUNCD grains and grain boundaries that was observed during our previous work (Figure 5a) [42]. In that work, we noticed an increase in BDUNCD grain capacitance or conductivity contributing to an increase in DA current. Beyond $6 \mathrm{~h}$, we observed a sharp decrease in the currents and sensitivity due to the BDUNCD surface fouling as was identified during previous work Figure 5b [14]. The poly-dopamine was deposited onto the BDUNCD electrode surface with time, which caused the background current to shift to more negative values $[14,18]$. As expected, it gradually blocked the current signals via the formation of melanin [14]. However, the nafion-modified BDUNCD microelectrode exhibited a stable signal with a higher DA

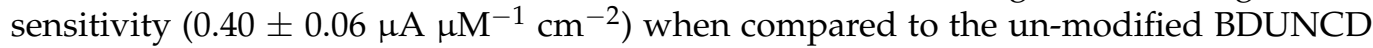
microelectrode $\left(0.30 \pm 0.18 \mu \mathrm{A} \mu \mathrm{M}^{-1} \mathrm{~cm}^{-2}\right)$ with a constant background current for the entire $9 \mathrm{~h}$ recording. This could be due to a reduction in the rate of surface fouling, thus increasing the electrode's useful lifetime. The negatively charged nafion layer rejected the negatively charged polydopamine, which otherwise fouled the microelectrode surface [18]. In addition, it reduced the chemical intermediates of o-dopaminoquinone (o-DQ), Leucodopaminochrome (LDC), and Dopaminochrome (DC) remaining on the surface that would otherwise form melanin and contributes to electrode fouling [14].

The nafion-MWCNT-modified BDUNCD microelectrode demonstrated the highest average currents and sensitivities, a 3-fold increase $\left(0.97 \pm 0.15 \mu \mathrm{A \mu M} \mathrm{M}^{-1} \mathrm{~cm}^{-2}\right)$ compared to the unmodified electrodes, and the sensitivity continued to increase during the entire $9 \mathrm{~h}$ recording (Table 2). This is due to a significant increase in the electroactive area as expected from the MWCNT layer [36,39], and the negatively charged nafion increased the adsorption of the positively charged DA. In addition, the nafion layer assisted in a reduction of the surface fouling. However, the signal varied continuously during the recording, and this could be due to the non-uniform, porous nature of the MWCNT layer with its inherent surface roughness and heterogeneity, which might affect the diffuse layer within the modified layers.

Table 2. Comparison of DA sensitivity, response time, and clearance rate during $9 \mathrm{~h}$ on the BDUNCD, nafion-modified BDUNCD, and nafion-MWCNT-modified BDUNCD electrodes $(n=3)$.

\begin{tabular}{cccc}
\hline Electrodes & $\mathbf{9} \mathbf{h}$ Sensitivity $\left(\boldsymbol{\mu} \mathbf{A} \boldsymbol{\mu} \mathbf{M}^{-\mathbf{1}} \mathbf{c m}^{-\mathbf{2}}\right)$ & Response Time $(\mathbf{s})$ & Clearance Rate $(\mathbf{s})$ \\
\hline BDUNCD & $0.30 \pm 0.18$ & $3.5 \pm 0.21$ & $1.7 \pm 0.34$ \\
Nafion-BDUNCD & $0.40 \pm 0.06$ & $2.5 \pm 0.15$ & $0.65 \pm 0.01$ \\
Nafion-MWCNT-BDUNCD & $0.97 \pm 0.15$ & $2 \pm 0.16$ & $3.35 \pm 1.81$ \\
\hline
\end{tabular}

\subsubsection{Response Time}

Response time is defined as the time for the sensor to increase in current from the background current level to that of the second oxidation peak current [43]. The nafion-MWCNTmodified BDUNCD microelectrode is shown in Figure 5c, which had the fastest response time $(2.0 \pm 0.16 \mathrm{~s})$ with good stability when compared to the unmodified BDUNCD microelectrode (3.5 $\pm 0.21 \mathrm{~s})$ and the nafion-modified BDUNCD microelectrode $(2.5 \pm 0.15 \mathrm{~s})$. Clearly, MWCNTs improved the response time, and this could be due to the ballistic electronic properties of MWCNTs [36,39]. A fast response time of less than a second to a few seconds is generally desirable for studying the in vivo neurotransmitter dynamics. These modified microelectrodes are excellent candidates for such demanding studies.

\subsubsection{Clearance Rate}

The clearance rate is defined as the time between $\mathrm{T}_{20}$ and $\mathrm{T}_{60}\left(\mathrm{~T}_{20}\right.$ is the signal reduced by $20 \%$ from the peak signal, and $\mathrm{T}_{60}$ is the signal reduced by $60 \%$ from the peak signal). 
From Figure $5 d$, the nafion-modified BDUNCD microelectrode had the fastest clearance rate $(0.65 \pm 0.01 \mathrm{~s})$. However, the nafion-MWCNT-modified BDUNCD microelectrode had the slowest clearance rate $(3.35 \pm 1.81 \mathrm{~s})$ compare to the unmodified BDUNCD microelectrode $(1.7 \pm 0.34 \mathrm{~s})$. The reason for this could be due to the porous, high-surface-roughness heterogeneous nature of the modified layers. Currently, we are optimizing the two modified layers to achieve a faster clearance rate that is desirable for neurochemical monitoring.

\subsection{Selectivity Measurements in a Ternary Mixture of DA, 5-HT, and AA}

All the three microelectrode types detected DA and 5-HT individually (single component) using the DPV method (Figure $6 \mathrm{a}-\mathrm{c}$ ) although with different sensitivities. Only the unmodified BDUNCD microelectrode detected AA and as expected, not those coated with nafion. The oxidation potentials of DA, 5-HT, and AA on the unmodified BDUNCD electrode were $52.49 \pm 2.62 \mathrm{mV}, 82.7 \pm 4.13 \mathrm{mV}$, and $47.5 \pm 2.38 \mathrm{mV}$, respectively. However, AA exhibited a large, broad current peak that completely overlapped DA and 5HT current signals (Figure 6a,d), and therefore the three current signals were undistinguishable (Figure 6d). Therefore, it is challenging for one to selectively detect DA and 5-HT in the presence of excess AA without electrode surface pre-treatment. In individual (single component) analyte solutions, the nafion-modified BDUNCD microelectrode demonstrated sharper and narrower DA and 5-HT current signals with reduced peak current values at $7.93 \pm 0.40 \mathrm{mV}$ and $77.66 \pm 3.88 \mathrm{mV}$, respectively (Figure 6b). However, in a ternary (multiple component) mixture with AA present, selective detection of DA and 5-HT with distinguishable current peaks (Figure 6e) was not achieved. This is due to a wider DA oxidation potential, which varied from $-164.03 \pm 3.28 \mathrm{mV}$ to $274.04 \pm 5.48 \mathrm{mV}$ and overlapped with the 5-HT signal. As expected, AA was rejected on the nafion-coated electrode, which therefore provided the necessary selectivity required for in vivo measurements. In contrast, the nafion-MWCNT-modified BDUNCD electrode exhibited sharper and narrower current peaks for both DA and 5-HT with the highest peak currents and sensitivities (Figure $6 \mathrm{c}$ ) in individual analyte solutions. The oxidation potentials of DA and 5-HT were $-83.47 \pm 4.67 \mathrm{mV}$ and $62.56 \pm 3.13 \mathrm{mV}$, respectively. In ternary mixtures with AA present, the distinguishable peaks for DA and 5-HT were retained with excellent selectivity and with respective oxidation potentials at $-12.97 \pm 0.02 \mathrm{mV}$ and $173.34 \pm 2.52 \mathrm{mV}$ [39] (Figure 6f). The peak oxidation current increased 5.5 times $(0.11 \pm 0.025 \mathrm{nA})$ for DA when compared to that of the unmodified BDUNCD microelectrode $(0.02 \pm 0.005 \mathrm{nA})$ and 3.3 times $(0.46 \pm 0.106 \mathrm{nA})$ for 5 -HT when compared to the unmodified BDUNCD microelectrode $(0.14 \pm 0.033 \mathrm{nA})$ (Table 3$)$. The DA and 5-HT sensitivities increased 165.5 times $\left(3.31 \pm 0.728 \mathrm{nA}, 6.75 \mu \mathrm{A} \mu \mathrm{M}^{-1} \mathrm{~cm}^{-2}\right)$ and 15.9 times $\left(2.23 \pm 0.468 \mathrm{nA}, 4.55 \mu \mathrm{A} \mu \mathrm{M}^{-1} \mathrm{~cm}^{-2}\right)$, respectively, when compared to the unmodified BDUNCD microelectrodes.

Table 3. Comparison of DPV peak currents from individual (single component) analytes (1 $\mu \mathrm{M} \mathrm{DA}, 1 \mu \mathrm{M} 5-\mathrm{HT}$, and $100 \mu \mathrm{M}$ ascorbic acid (AA)).

\begin{tabular}{ccccc}
\hline Electrode & $\begin{array}{c}\text { DA Current (nA) } \\
(\mathbf{1} \boldsymbol{\mu M})\end{array}$ & $\begin{array}{c}\text { 5-HT Current (nA) } \\
(\mathbf{1} \boldsymbol{\mu M})\end{array}$ & $\begin{array}{c}\text { AA Current (nA) } \\
(\mathbf{1 0 0} \boldsymbol{\mu M})\end{array}$ & $\begin{array}{c}\text { DA Sensitivity Value } \\
\boldsymbol{\mu} \mathbf{M} \boldsymbol{\mu} \mathbf{M}^{-\mathbf{1}} \mathbf{c m}^{-\mathbf{2}}\end{array}$ \\
\hline BDUNCD & $0.02 \pm 0.005$ & $0.14 \pm 0.033$ & $0.17 \pm 0.038$ & 0.04 \\
Nafion-BDUNCD & $0.11 \pm 0.025$ & $0.46 \pm 0.106$ & N/A & 0.22 \\
Nafion-MWCNT-BDUNCD & $3.31 \pm 0.728$ & $2.23 \pm 0.468$ & N/A & 6.75 \\
\hline
\end{tabular}



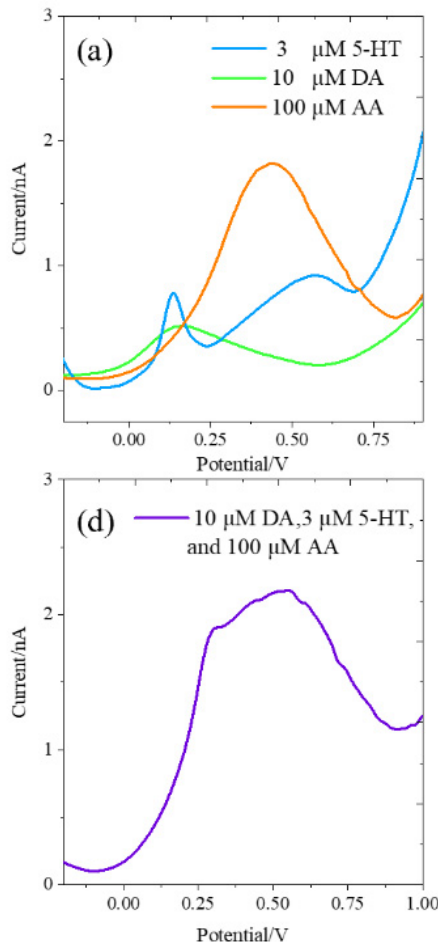
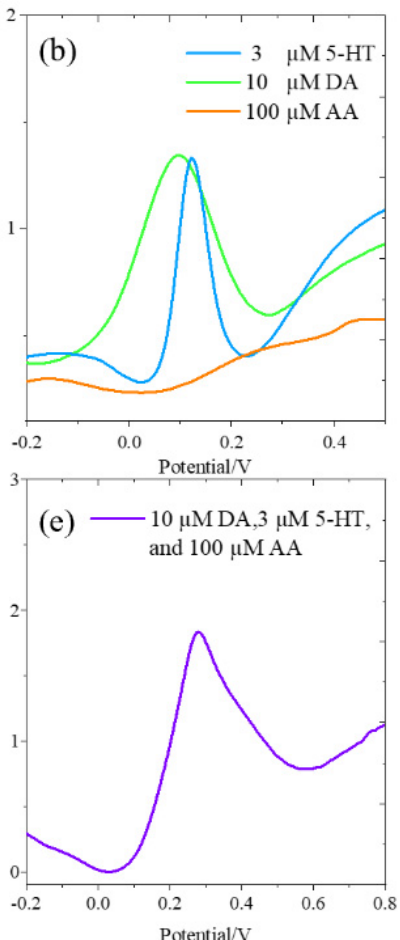
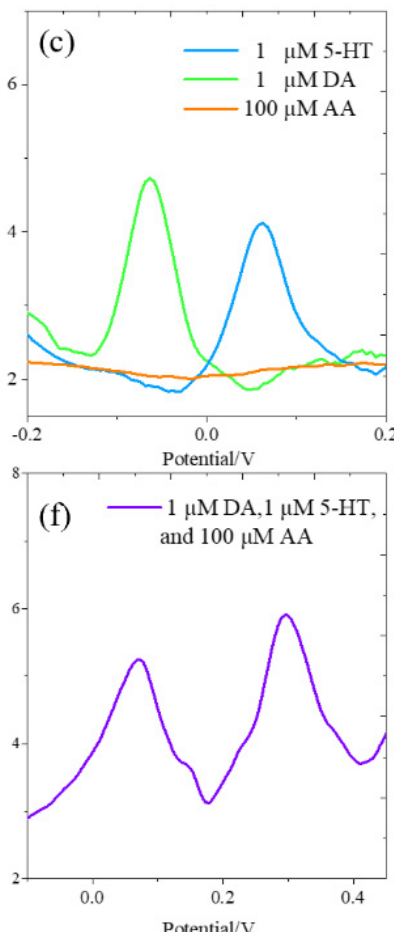

Figure 6. Differential pulse voltammetry (DPV) plots of the unmodified (a,d), nafion-modified (b,e), and nafion-MWCNT-modified (c,f) BDUNCD microelectrodes using individual analytes (a-c) and ternary mixture (d-f) in the solution. For nafion-MWCNT-modified BDUNCD microelectrodes, lower concentrations of DA and serotonin (5-HT) were used.

Long-Term DA and 5-HT Measurements

A long-term study was conducted to evaluate the sensor metrics of nafion-MWCNTmodified BDUNCD microelectrodes (Figure 7). The DPV voltammograms for sampling times of $0,3,6$, and $9 \mathrm{~h}$ in a ternary mixture of $1 \mu \mathrm{M} \mathrm{DA}, 1 \mu \mathrm{M} 5-\mathrm{HT}$, and $100 \mu \mathrm{M}$ AA were collected. Before the experiments, the microelectrodes were cleaned in a 1X PBS solution with a flow rate of $0.1 \mathrm{~mL} / \mathrm{min}$ for $20 \mathrm{~min}$. The initial DA and 5-HT peak currents were $0.58 \pm 0.03 \mathrm{nA}$ and $1.03 \pm 0.06 \mathrm{nA}$, respectively, and the initial DA and 5-HT sensitivities

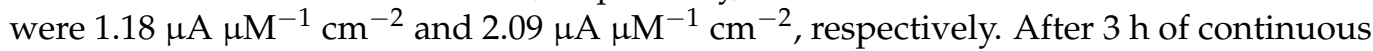
use, the DA and 5-HT signals decreased by $28 \%$ and $0.06 \%$, respectively, which could be due to some loss of surface - $\mathrm{COOH}$ functional groups of the MWCNT layer that would aid in DA adsorption. However, after $9 \mathrm{~h}$, the DA and 5-HT signals decreased by $47 \%$ and $26 \%$, respectively. The fouling was much less significant when compared to our earlier work [14] on BDUNCD surface stability, where we observed a 50\% reduction in DA signals during the $2 \mathrm{~h}$ intentional surface fouling via the amperometry detection method. In this work, we have demonstrated that by suitable surface modifications, BDUNCD microelectrode lifetime can be significantly increased ( 4-fold). Further optimization of the coatings is in progress to reduce the surface loss and the sensor metrics in the future. We, therefore, have demonstrated the importance of modifying BDUCND microelectrodes with nafion and MWCNT and their utility for long-term DA and 5-HT detection. 


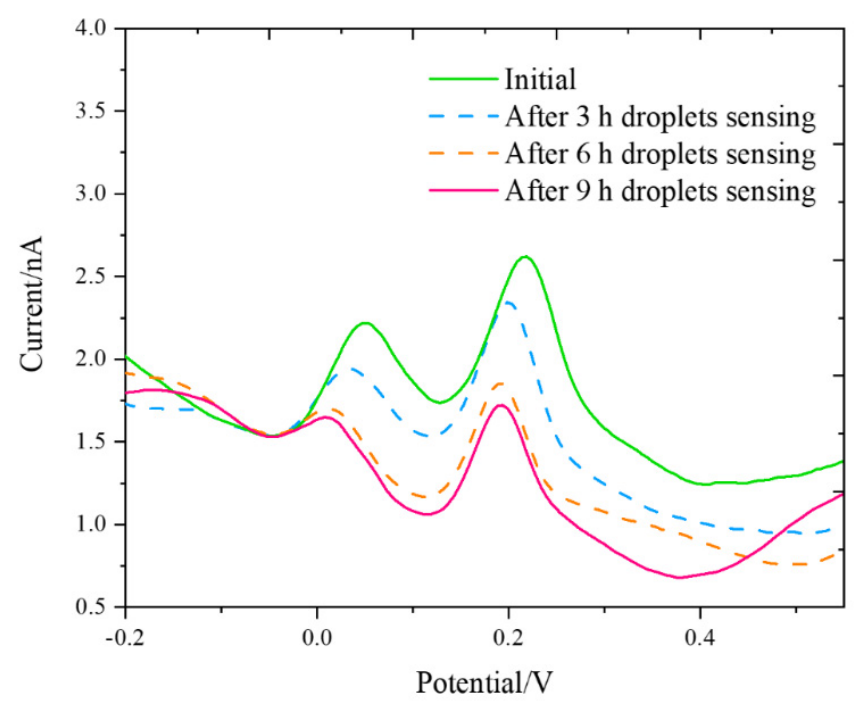

Figure 7. DPV plots of the nafion-MWCNT-modified BDUNCD microelectrode in a ternary mixture of $1 \mu \mathrm{M} 5-\mathrm{HT}, 100 \mu \mathrm{M} \mathrm{AA}$, and $1 \mu \mathrm{M} \mathrm{DA}$ and at 0th, 3rd, 6th, and 9th $\mathrm{h}$. The flow rate was $0.1 \mathrm{~mL} / \mathrm{min}$ with a droplet volume of $0.02 \mathrm{~mL}$, a background flow rate of $0.1 \mathrm{~mL} / \mathrm{min}$, and a potential of $+0.35 \mathrm{~V}$ with a droplet frequency of $2 \mathrm{~min}$.

\subsection{LoD and Limit of Quantification (LoQ) for DA Detection}

The LoD is the lowest analyte concentration for which a signal is likely to be reliably distinguishable from the Limit of Blank. The lowest DA concentration detectable on the nafion-MWCNT-modified BDUNCD microelectrode was $1 \mathrm{nM}$ DA with a peak current of $0.06 \pm 0.01 \mathrm{nA}$, and a LoD of $5.4 \pm 0.40 \mathrm{nM}$. The LoD was calculated using Standard Deviation/slope times 3 [44], which was three times the standard deviation divided by the slope. The LoQ is the lowest concentration at which the analyte cannot only be reliably detected but at which some predefined goals for bias and imprecision are met. By varying the DA concentration from $1 \mathrm{nM}$ to $50 \mathrm{nM}$, we measured the LoQ to be $18.9 \pm 1.78 \mathrm{nM}$.

\section{Conclusions}

We developed a droplet-based microfluidic platform to investigate three types of BDUNCD microelectrodes modified with nafion and MWCNTs for long-duration highsensitivity neurochemical measurements in vitro. The nafion-modified BDUNCD microelectrode exhibited the highest sensitivity and selectivity towards DA and 5-HT in the presence of excessive AA. We observed the least amount of surface fouling with good signal stability and significant current enhancement with a nafion coating. Remarkable DA and 5-HT sensitivity and selectivity were achieved by incorporating an MWCNT layer. Our nafionMWCNT-modified BDUNCD microelectrode recorded a 166-fold and 16-fold increase in DA and 5-HT sensitivity, respectively $\left(6.75 \mu \mathrm{A} \mu \mathrm{M}^{-1} \mathrm{~cm}^{-2}\right.$ and $4.55 \mu \mathrm{A} \mu \mathrm{M}^{-1} \mathrm{~cm}^{-2}$, respectively) when compared to the unmodified BDUNCD microelectrode $\left(0.04 \mu \mathrm{A} \mu \mathrm{M}^{-1} \mathrm{~cm}^{-2}\right)$. Furthermore, we observed distinguishable DA and 5-HT current peaks during the long-term stability studies (up to $9 \mathrm{~h}$ ) with the nafion-MWCNT electrode surface modification. The ability to monitor neurochemicals with excellent long-term sensitivity and selectivity will allow this modified diamond microelectrode to become an important tool for exploring the effects of stimulation and drugs on neuronal networks and for expanding our understanding of neuronal changes in the brain for both healthy and diseased states.

Author Contributions: Conceptualization, P.U.A., A.-Y.C., and S.S.; data curation, A.-Y.C. and P.U.A.; writing of the original draft preparation, A.-Y.C. and P.U.A.; writing of review and editing, all authors. All authors have read and agreed to the published version of the manuscript. 
Funding: This work was supported by the National Science Foundation through the OIA/EPSCoR grant 1632891 on Probing and Understanding the Brain: Micro and Macro Dynamics of Seizure and Memory Networks.

Institutional Review Board Statement: Not applicable.

Informed Consent Statement: Not applicable.

Data Availability Statement: Not applicable.

Acknowledgments: The authors thank Leon Iasemidis, the Director of the Center for Biomedical Engineering and Rehabilitation Sciences (CBERS) and the Principal Investigator of the NSF grant that funded this work. We thank Chao Tan for his assistance in the development of EPD processes for MWCNT coatings.

Conflicts of Interest: The authors declare no conflict of interests.

\section{References}

1. Deserno, L.; Huys, Q.J.M.; Boehme, R.; Buchert, R.; Heinze, H.-J.; Grace, A.A.; Dolan, R.J.; Heinz, A.; Schlagenhauf, F. Ventral striatal dopamine reflects behavioral and neural signatures of model-based control during sequential decision making. Proc. Natl. Acad. Sci. USA 2015, 112, 1595-1600. [CrossRef]

2. Barbeau, A. The pathogenesis of Parkinson's disease: A new hypothesis. Can. Med. Assoc. J. 1962, 87, 802-807.

3. Othman, A.A.; Chatamra, K.; Mohamed, M.-E.F.; Dutta, S.; Benesh, J.; Yanagawa, M.; Nagai, M. Jejunal Infusion of LevodopaCarbidopa Intestinal Gel Versus Oral Administration of Levodopa-Carbidopa Tablets in Japanese Subjects with Advanced Parkinson's Disease: Pharmacokinetics and Pilot Efficacy and Safety. Clin. Pharmacokinet. 2015, 54, 975-984. [CrossRef] [PubMed]

4. Bódi, N.; Kéri, S.; Nagy, H.; Moustafa, A.; Myers, C.E.; Daw, N.; Dibó, G.; Takáts, A.; Bereczki, D.; Gluck, M.A. Reward-learning and the novelty-seeking personality: A between- and within-subjects study of the effects of dopamine agonists on young Parkinson's patients. Brain 2009, 132, 2385-2395. [CrossRef] [PubMed]

5. Lang, A.E.; Lees, A. Anticholinergic therapies in the treatment of Parkinson's disease. Management of Parkinson's disease: An evidence-based review. Mov. Disord. 2002, 17. [CrossRef]

6. Dugast, C.; Suaud-Chagny, M.; Gonon, F. Continuousin vivo monitoring of evoked dopamine release in the rat nucleus accumbens by amperometry. Neuroscience 1994, 62, 647-654. [CrossRef]

7. Bucur, B. Technological Barriers in the Use of Electrochemical Microsensors and Microbiosensors for in vivo Analysis of Neurological Relevant Substances. Curr. Neuropharmacol. 2012, 10, 197-211. [CrossRef]

8. Robinson, D.L.; Venton, B.J.; Heien, M.L.; Wightman, R.M. Detecting Subsecond Dopamine Release with Fast-Scan Cyclic Voltammetry in Vivo. Clin. Chem. 2003, 49, 1763-1773. [CrossRef]

9. Rodeberg, N.T.; Sandberg, S.G.; Johnson, J.A.; Phillips, P.E.M.; Wightman, R.M. Hitchhiker's Guide to Voltammetry: Acute and Chronic Electrodes for in Vivo Fast-Scan Cyclic Voltammetry. ACS Chem. Neurosci. 2017, 8, 221-234. [CrossRef]

10. Koehne, J.E.; Marsh, M.; Boakye, A.; Douglas, B.; Kim, I.Y.; Chang, S.-Y.; Jang, D.-P.; Bennet, K.E.; Kimble, C.; Andrews, R.; et al. Carbon nanofiber electrode array for electrochemical detection of dopamine using fast scan cyclic voltammetry. Analyst 2011, 136, 1802-1805. [CrossRef]

11. Carlisle, J.A.; Auciello, O. Ultrananocrystalline diamond. Interface Electrochem. Soc. 2003, 12, 28-32. [CrossRef]

12. Siddiqui, S.; Dai, Z.; Stavis, C.J.; Zeng, H.; Moldovan, N.; Hamers, R.J.; Carlisle, J.A.; Arumugam, P.U. A quantitative study of detection mechanism of a label-free impedance biosensor using ultrananocrystalline diamond microelectrode array. Biosens. Bioelectron. 2012, 35, 284-290. [CrossRef]

13. Yang, W.; Auciello, O.; Butler, J.E.; Cai, W.; Carlisle, J.A.; Gerbi, J.E.; Gruen, D.M.; Knickerbocker, T.; Lasseter, T.L.; Russell, J.N.; et al. Erratum: DNA-modified nanocrystalline diamond thin-films as stable, biologically active substrates. Nat. Mater. $2003,2,63$. [CrossRef]

14. Chang, A.-Y.; Dutta, G.; Siddiqui, S.; Arumugam, P.U. Surface Fouling of Ultrananocrystalline Diamond Micro-electrodes during Dopamine Detection: Improving Lifetime via Electrochemical Cycling. ACS Chem. Neurosci. 2018, 10, 313-322. [CrossRef]

15. Bennet, K.E.; Tomshine, J.R.; Min, H.-K.; Manciu, F.S.; Marsh, M.P.; Paek, S.B.; Settell, M.L.; Nicolai, E.N.; Blaha, C.D.; Kouzani, A.Z.; et al. A Diamond-Based Electrode for Detection of Neurochemicals in the Human Brain. Front. Hum. Neurosci. 2016, 10, 102. [CrossRef] [PubMed]

16. Tan, S.M.; Poh, H.L.; Sofer, Z.; Pumera, M. Boron-doped graphene and boron-doped diamond electrodes: Detec-tion of biomarkers and resistance to fouling. Analyst 2013, 138, 4885. [CrossRef]

17. Keefer, E.W.; Botterman, B.R.; Romero, M.I.; Rossi, A.F.; Gross, G.W. Carbon nanotube coating improves neuronal recordings. Nat. Nanotechnol. 2008, 3, 434-439. [CrossRef] [PubMed]

18. Chang, A.-Y.; Arumugam, P. Fabrication and characterization of boron-doped ultrananocrystalline diamond microelectrodes modified with multi-walled carbon nanotubes and nafion. Biosens. Nanomed. XI 2018, 10728, 1072803. [CrossRef]

19. Boccaccini, A.R.; Cho, J.; Roether, J.A.; Thomas, B.J.; Minay, E.J.; Shaffer, M.S. Electrophoretic deposition of carbon nanotubes. Carbon 2006, 44, 3149-3160. [CrossRef] 
20. Pihel, K.; Walker, Q.D.; Wightman, R.M. Overoxidized Polypyrrole-Coated Carbon Fiber Microelectrodes for Dopamine Measurements with Fast-Scan Cyclic Voltammetry. Anal. Chem. 1996, 68, 2084-2089. [CrossRef] [PubMed]

21. Cho, J.; Konopka, K.; Rożniatowski, K.; García-Lecina, E.; Shaffer, M.S.; Boccaccini, A.R. Characterisation of carbon nanotube films deposited by electrophoretic deposition. Carbon 2009, 47, 58-67. [CrossRef]

22. Boccaccini, A.; Cho, J.; Subhani, T.; Kaya, C.; Kaya, F. Electrophoretic deposition of carbon nanotube-ceramic nanocomposites. J. Eur. Ceram. Soc. 2010, 30, 1115-1129. [CrossRef]

23. Bareket-Keren, L.; Hanein, Y. Carbon nanotube-based multi electrode arrays for neuronal interfacing: Progress and prospects. Front. Neural Circuits 2013, 6, 122. [CrossRef] [PubMed]

24. Zhang, Y.; Franklin, N.W.; Chen, R.J.; Dai, H. Metal coating on suspended carbon nanotubes and its implication to metal-tube interaction. Chem. Phys. Lett. 2000, 331, 35-41. [CrossRef]

25. Harreither, W.; Trouillon, R.; Poulin, P.; Neri, W.; Ewing, A.G.; Safina, G. Carbon Nanotube Fiber Microelectrodes Show a Higher Resistance to Dopamine Fouling. Anal. Chem. 2013, 85, 7447-7453. [CrossRef] [PubMed]

26. Chandra, S.; Miller, A.D.; Bendavid, A.; Martin, P.J.; Wong, D.K.Y. Minimizing Fouling at Hydrogenated Conical-Tip Carbon Electrodes during Dopamine Detection in Vivo. Anal. Chem. 2014, 86, 2443-2450. [CrossRef] [PubMed]

27. Ben-Jacob, E.; Hanein, Y. Carbon nanotube micro-electrodes for neuronal interfacing. J. Mater. Chem. 2008, 18, 5181-5186. [CrossRef]

28. Luong, J.H.; Male, K.B.; Glennon, J.D. Biosensor technology: Technology push versus market pull. Biotechnol. Adv. 2008, 26, 492-500. [CrossRef] [PubMed]

29. Teles, F.; Fonseca, L. Trends in DNA biosensors. Talanta 2008, 77, 606-623. [CrossRef]

30. Schasfoort, R.B.M. Proteomics-on-a-chip: The challenge to couple lab-on-a-chip unit operations. Expert Rev. Proteom. 2004, 1, 123-132. [CrossRef] [PubMed]

31. Wang, J. Electrochemical biosensors: Towards point-of-care cancer diagnostics. Biosens. Bioelectron. 2006, 21, 1887-1892. [CrossRef]

32. Van Der Helm, M.W.; Van Der Meer, A.D.; Eijkel, J.C.; Berg, A.V.D.; Segerink, L.I. Microfluidic organ-on-chip technology for blood-brain barrier research. Tissue Barriers 2016, 4, e1142493. [CrossRef]

33. Dutta, G.; Siddiqui, S.; Zeng, H.; Carlisle, J.A.; Arumugam, P.U. The effect of electrode size and surface heterogeneity on electrochemical properties of ultrananocrystalline diamond microelectrode. J. Electroanal. Chem. 2015, 756, 61-68. [CrossRef]

34. Choi, W.B.; Jin, Y.W.; Yun, M.J.; Choi, Y.S.; Park, N.S.; Lee, N.S.; Kim, J.M.; Kim, H.Y.; Lee, S.J.; Kang, J.H. Electrophoresis deposition of carbon nanotubes for triode-type field emission display. Appl. Phys. Lett. 2001, 78, 1547-1549. [CrossRef]

35. Zhao, H.; Song, H.; Li, Z.; Yuan, G.; Jin, Y. Electrophoretic deposition and field emission properties of patterned car-bon nanotubes. Appl. Surf. Sci. 2005, 251, 242-244. [CrossRef]

36. Tan, C.; Dutta, G.; Yin, H.; Siddiqui, S.; Arumugam, P.U. Detection of neurochemicals with enhanced sensitivity and selectivity via hybrid multiwall carbon nanotube-ultrananocrystalline diamond microelectrodes. Sens. Actuators B Chem. 2018, 258, 193-203. [CrossRef] [PubMed]

37. Cheng, W.-C.; He, Y.; Chang, A.-Y.; Que, L. A microfluidic chip for controlled release of drugs from microcapsules. Biomicrofluidics 2013, 7, 64102. [CrossRef] [PubMed]

38. Rand, E.; Periyakaruppan, A.; Tanaka, Z.; Zhang, D.A.; Marsh, M.P.; Andrews, R.J.; Lee, K.H.; Chen, B.; Meyyappan, M.; Koehne, J.E. A carbon nanofiber based biosensor for simultaneous detection of dopamine and serotonin in the presence of ascorbicacid. Biosens. Bioelectron. 2013, 42, 434-438. [CrossRef] [PubMed]

39. Chang, A.-Y.; Liu, X.; Pei, Y.; Gong, C.; Arumugam, P.U.; Wang, S. Dopamine sensing with robust carbon nanotube implanted polymer micropillar array electrodes fabricated by coupling micromolding and infiltration coating processes. Electrochim. Acta 2021, 368, 137632. [CrossRef]

40. Cho, W.; Liu, F.; Hendrix, A.; McCray, B.; Asrat, T.; Connaughton, V.; Zestos, A.G. Timed Electrodeposition of PEDOT:Nafion onto Carbon Fiber-Microelectrodes Enhances Dopamine Detection in Zebrafish Retina. J. Electrochem. Soc. 2020, 167, 115501. [CrossRef] [PubMed]

41. Adams, K.L.; Puchades, M.; Ewing, A.G. In Vitro Electrochemistry of Biological Systems. Annu. Rev. Anal. Chem. 2008, 1, 329-355. [CrossRef] [PubMed]

42. Dutta, G.; Tan, C.; Siddiqui, S.; Arumugam, P.U. Enabling long term monitoring of dopamine using dimensionally stable ultrananocrystalline diamond microelectrodes. Mater. Res. Express 2016, 3, 094001-005. [CrossRef] [PubMed]

43. Sensor Terminology. Sensor Terminology—National Instruments. Available online: http://www.ni.com/white-paper/14860/en/ (accessed on 18 June 2017).

44. Magnusson, B.; Örnemark, U. (Eds.) Eurachem Guide: The Fitness for Purpose of Analytical Methods_Eurachem, 2nd ed.; Teddington: Middlesex, UK, 2014; Available online: https:/ / www.eurachem.org/images/stories/Guides/pdf/MV_guide_2nd_ed_EN.pdf (accessed on 26 June 2019). 